\title{
The impact of huge transport PPP projects on Russian Federation development socio-economic
}

\author{
Alisa Sablina ${ }^{1, *}$, and Viktor Dubolazov ${ }^{1}$ \\ ${ }^{1}$ Peter the Great St. Petersburg Polytechnic University, Polytechnicheskaya str., 29, 195251, Saint- \\ Petersburg, Russia
}

\begin{abstract}
This article describes the main impact peculiarities of huge transport projects implemented by public-private partnership on Russian Federation socio - economic development. The research was based on the deep data analysis of changing socio-economic indicators of six different Russian regions (including regions of different federal districts), where were implemented (or are being implemented) of huge transport infrastructure projects, implemented by public-private partnership over the past 10 years. The method of statistical data analysis, obtained in the research, was conduct by using STATISTICA software package, Federal state statistics service information and Public-private partnership platform of infrastructural projects in Russian Federation.
\end{abstract}

\section{Introduction}

In the 90s of the 20th century the policy of the Russian Federation was reoriented towards a market economy, so methods of huge infrastructure projects evaluation was formed in a separate direction of economic management [1].

Wear and tear, as well as the lack of infrastructure capacity in various sectors, especially in transport construction, requires the development and implementation of new infrastructure projects, which, like any other planned for construction projects, require a comprehensive assessment, before, during and after their implementation. Actually huge infrastructure projects evaluation are usually not profitable from the commercial point of view (for the various participants in its implementation), but perform socially important functions, which are important for the country and regions development, and are also vital for the public, who can use its services [2].

Methods of projects evaluation from the commercial point of view have been studied in details and covered in scientific literature by domestic and foreign scientists [3].

Nevertheless, from the point of view of socio-economic effects generated by such projects, as well as obtaining a cumulative assessment of the project, which reflects its impact on both the micro and macroeconomic levels, is still being under study [4].

Nowadays, there are lots of huge infrastructure projects evaluation methods, which are used, however, all methods should be applied primarily on the basis of the prerequisites for

\footnotetext{
*Corresponding author: lisa_alisa_23@mail.ru
} 
the construction of these projects, the territorial component and the method of financing [5].

Also, the most common form of huge infrastructure projects evaluation is to assess their effectiveness, by using a wide range of existing author's techniques, as well as techniques established at the legislative level (for example, in the implementation of projects through PPP). Among foreign scientists, who studied methods of projects effectiveness evaluation, should be noted Birman G., Schmidt S., Pigou A., R. Coase, etc. Among Russian scientists should be noted Vilensky P.L., Volkov V.I, Smolyak S.A, Trofimov V.P., Kossov V.V, Gulakova O.I., etc [6].

Contemporary methods of projects effectiveness evaluation are not enshrined at the legislative level [7]. The main idea of the concept of projects effectiveness evaluation is in accordance with the draft of its goals and objectives set at the initial stage. It is assumed that the effectiveness can be assessed from different sides - as a calculation of the effectiveness of the project, as a calculation of efficiency for each of the project participants, as a calculation of the effectiveness for the final services consumers.

In huge infrastructure projects, the calculation of efficiency is based on the calculation of various factors that allow to evaluate the project from the economic, social, scientific and technical, investment and other points of efficiency.

Among lots of present methods of projects effectiveness evaluation, should be highlighted some authors methods (including foreign and Russian) and also enshrined in law methods:

\subsection{Foreign practice}

- Value for Money conception (VfM) - this conception implies the ratio of cost and quality of the project [8];

- Cost-benefit analysis (CBA) - this method is based on the comparison of revenues and expenditures for the project;

- Cost-effectiveness analysis (CEA) - this method is based on the determination of the optimal resource component consumption in the project implementation to achieve the objectives [9];

- Cost-utility analysis (CUA) - this method is focused on the project in comparison with the units of utility for the recipients of the project services (population). As a result of the calculation of this ratio, conditional indicators are obtained and help to assess the specifics of project implementation.

\subsection{Russian practice}

Methodology of evaluating the effectiveness of public-private partnership project, municipalprivate partnership project and determining their comparative advantage - this method was approved by the order of the Ministry of economic development of the Russian Federation of November 30, 2015 № 894. Evaluation of the project effectiveness is carried out before determining the comparative advantage of the project on the basis of the following criteria:

- financial efficiency of the project;

- socio - economic effect from implementation of the project [10].

- methodology by Andreeva V.S. (authors methodology) - the methodology involves the division of the calculated performance indicators into two groups:

- performance indicators of PPP projects for the state;

- indicators of efficiency of PPP projects for the business [11].

- Author's method of selection and evaluation of the effectiveness of public-private partnership projects taking into account the interests of stakeholders, Tkachenko I. N., Savchenko Ya.V. This methodology includes the following provisions:

- the necessity to comply with efficiency both for the state and business and for society; 
- the main objective of the project - socio-economic development of the region;

- when evaluating the project, it is necessary not to go beyond resource constraints [12].

In according to all mentioned above methods of huge infrastructure project evaluation, the evaluation of any project should include a comprehensive assessment, both at the micro and macro levels, which allows to assess the effectiveness of the project directly to its participants (analysis of the economic, budgetary, etc. effectiveness), as well as the impact on the industry, and socio-economic development of the subject in which the project is planned to be implemented.

The object of accomplished research is huge infrastructure projects in transport sphere HTIP - which can be defined as the long-term, capital-intensive, transport construction project, difficult in technical implementation, carried out by two and more participants of the market relations, defining balanced development, competitiveness and improvement of social and economic indicators of the Russian Federation regions or the country as a whole, by improvement of transport indicators and adjacent branches. The implementation of HTIP is usually made with an involvement of mixed financing, especially with the use of publicprivate partnership mechanism (PPP).

The main point of conducting this research was to determine the effectiveness of such projects and their impact on socio-economic development of the Russian Federation regions and also to withdraw dependencies by grouping HTIP by types of their impact on such regions. These patterns could not be identified without a retrospective statistical analysis. Key points of this research can be found further.

\section{An experimental section}

The determination of HTIP influence on social and economic regions development can be defined by drawing up the correlation and regression analysis, representing the classical method of stochastic modeling studying interrelations of the considered indicators when dependence between them is not strictly functional and is distorted by influence of extraneous, random factors [8].

In this research the influence of HTIP on regional development is considered in dynamics from 2006 to 2016 . The analysis is based on indicators of social and economic development of the Russian Federation regions. As a representative group were selected only those regions in which during the specified period HTIPs are being implemented. Conducted research with the help of statistical models allowed to estimate the impact of the HTIPs implementation on a number of social and economic indicators characterizing the level of development of the Russian Federation regions.

Among the areas under consideration were chosen:

- Voronezh oblast (Central Federal district);

In this area, 2 HTIPs are implemented in the field of road infrastructure, both projects are implemented through the conclusion of an investment agreement. The years of implementation - 2011 (for 10 years), 2013 (for 23 years);

- Moscow (Central Federal district);

In this area, 4 HTIPs are implemented -3 projects in the field of road infrastructure and 1 project in the inner city field. The years of implementation - 2014 (for 30 years), 2015 (for 40 years), 2016 ( 2 projects for 3 and 4 years). The forms of implementation of all projects are different - there are an investment agreement, Life cycle contracts and corporate partnership;

- Saint Petersburg (Northwestern Federal district);

In this area, 4 HTIPs are implemented - in the areas of road, aviation and urban infrastructure. The years of implementation - 2012 (2 projects for 42 and 12 years), 2010 (for 30 years), 2016 (for 29 years). The forms of implementation of all projects are different - 
PPP contracts and concessions.

- Samara oblast (Volga Federal district);

Currently, 1 project in the field of aviation infrastructure is being implemented in the Samara region through the conclusion of an investment agreement. Year of implementation -2012 (for 5 years).

- Republic of Altai (Siberian Federal district);

In the Altai Republic are currently being implemented 2 CHIP

in the areas of aviation and road infrastructure, with implementation dates - 2011 (7 years), 2016 (7 years). Forms of implementation of KTIP - investment agreement;

- Amur region (far Eastern Federal district);

In this area, 2 HTIPs are implemented in the area of road infrastructure with the use of concession agreements. Years of implementation - 2012 (for 8 years), 2016 (for 30 years).

All this regions belongs to different Federal districts and are unique in the way of project implementations. In order to conduct a research was used a statistical database of these regions in dynamics of the last 10 years (from 2006 to 2016 years). The correlation and regression analysis revealed the relationship between the indicator «Investments in fixed assets: transport» and the selected by author indicators.

HTIPs also require a huge financial investment, and considered to be implemented with the budget finance involvement. So, such projects obviously affects the economy of region, and conducted research helps to identify these patterns. The research was made by using software package of statistical analysis «STATISTICA». Each indicator from the selected group of economic and social indicators for all regions was compared with the indicator «Investment in fixed assets: transport». In the analysis were used methods of constructing linear, power and exponential regression models.

This analysis also includes calculating indicators of correlation and determination to determine the range of factors that affect the feature-the result of the assessment of their degree of influence.

The formula of the pair correlation coefficient is:

$$
r=\frac{\sum_{i=1}^{n}\left(\frac{\left.x_{i}-\bar{x}\right)}{\sigma_{x}}\right)\left(\frac{\left.y_{i}-\bar{y}\right)}{\sigma_{y}}\right)}{n}
$$

where

$\sigma_{x}, \sigma_{y}$ - mean quadratic deviations of the characteristic factor and the characteristic result;

$n$ - is the number of statistical units.

The correlation coefficient changes within:

$0 \leq|r| \leq 1$, in the case of $r=0$, then the relation between the studied characteristics is missing. If $|r|=1$, the relationship is functional - the value of the dependent variable is completely determined by the value of the independent variable. A positive value is a direct correlation, a negative is the opposite.

The square of correlation coefficient $r^{2}$ is called the coefficient of determination [15].

The value of the determination coefficient $\left(R^{2}\right)$ varies from 0 to 1 and determines the proportion of variation of the effective characteristic due to the variation of the characteristic factor.

\section{Results}

According to the conducted analysis was considered:

- in terms of economic indicators: the existence of a link between indicators can be seen in almost all the selected regions. The least connections were discovered at Saint-Petersburg and the Republic of Altai. 
- on social indicators: the most correlation connections were revealed in the Samara region (with 3 indicators from 6), in all other regions with almost 1 indicator from various categories.

Nevertheless, the conducted analysis shows that the greatest impact on the indicators characterizing the economic status of regions was detected, despite the opposite situation in the block of social indicators.

The presence of a greater number of correlations on economic indicators was revealed mostly in small areas, where the implementation of the HTIP (through PPP) is a one-time occurrence. The exception is Moscow (4 HTIPs) - this city showed the best connections on all economic indicators. This trend could be explained by the growth of all economic spheres and large investments in the transport industry. The recorded growth of all considered economic indicators characterizes the presence of correlations on the economic block. This situation you can see on Fig. 1.

The indicators in economic development, Moscow (2006-2016.)

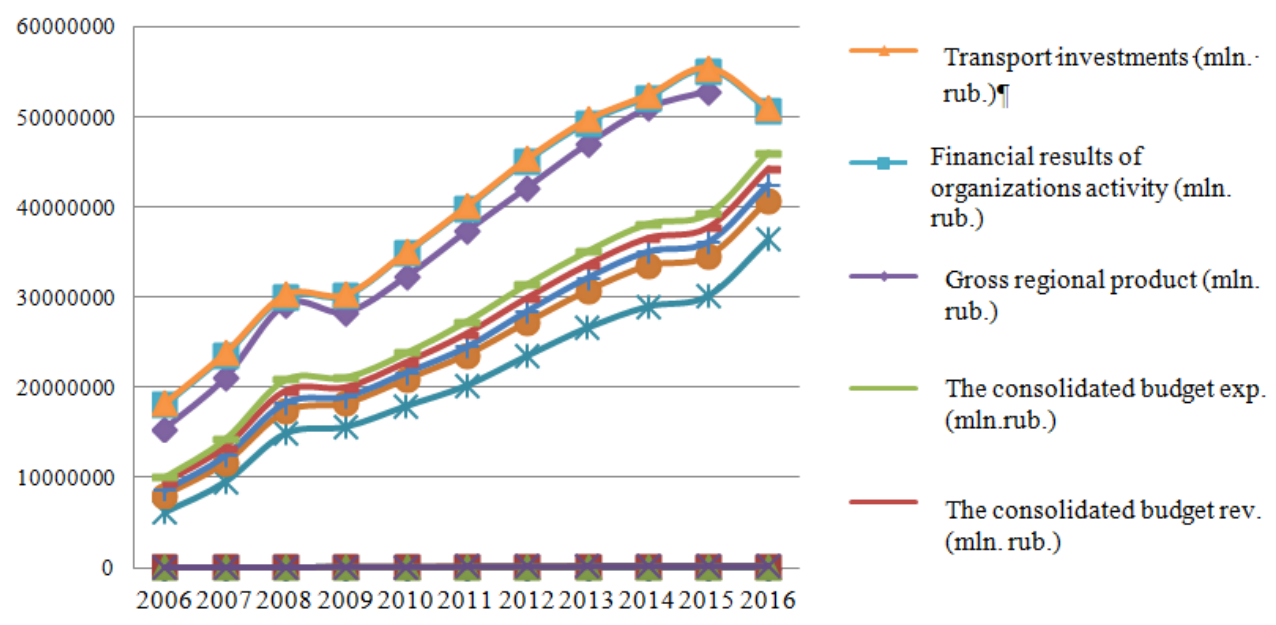

Fig. 1. The change of indicators characterizing the economic condition of Moscow (2006-2016).

The opposite situation is observed in St. Petersburg (4 HTIPs) - this region showed the lowest correlation on economic indicators. This trend is explained by the uneven development of the considered indicators from 2006 to 2016, especially the uneven development of the indicator «Investments in fixed assets: transport», which coincides with the crisis situation in 2008 and 2012. Nevertheless, in 2016 there is a sharp increase in the transport sector investments, which leads to the conclusion about the possibility of recovery from the crisis state for future periods. This situation is confirmed on the Fig. 2.

Comparing both figures, we can see that the volume of the indicator «Investment in fixed assets: transport» in Saint-Petersburg is much lower than in Moscow, accordingly, the correlation in Moscow is closer. On social indicators, the analysis did not reveal significant correlations in most areas, with the exception of Samara region.

According to the study, the gross regional product (GRP) occupies a key place among the factors of economic development of the Russian Federation regions. This occurs due to the influence of the investment process on changing the GRP dynamics. However, there is a high correlation of other factors that indirectly affect the change of GRP in the region, namely investments in fixed assets, the consolidated budget changes, income of citizens, trade turnover in the region, etc. 
However, there is no correlation with a number of social factors.

Such projects as HTIP are evaluated in the accordance to its commercial (economic) indicators and the social block is limited to the calculation of achievement of state or municipal programs indicators.

\section{The indicators of economic development, Saint-P (2006-2016)}

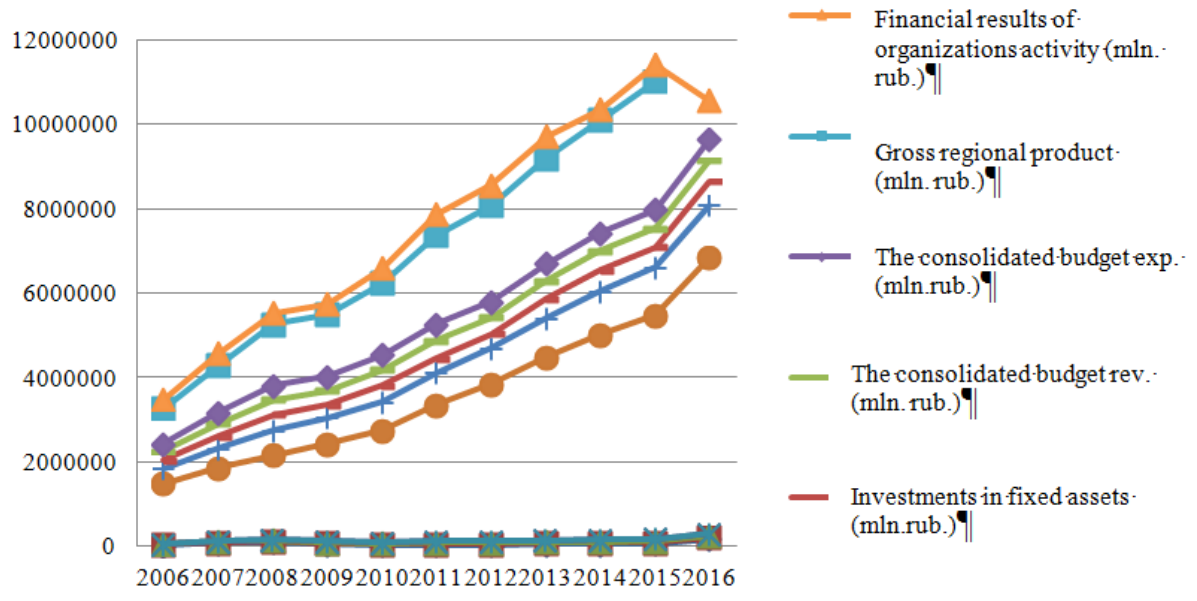

Fig. 2. The change of indicators characterizing the economic condition of Saint-P. (2006 - 2016).

However, such methods do not take into account the impact of HTIPs on mortality, fertility, economically active population, unemployment, as well as the common public needs. But these indicators also influence the development of the region and increase its wellbeing by attracting new labor resources and creating a favorable environment for further economic investments.

Accordingly, in addition to the calculation of the financial model of such projects, it is necessary to consider the block of social development, especially those indicators in which no correlation was detected:

- Population change;

- Total fertility rates;

- Total mortality rates;

- Average annual number of employed persons;

- Unemployment rate.

However, it is not possible to develop coefficients for indicators that depends on natural causes, but it is necessary to propose the use of criteria that would characterize HTIPs in terms of public satisfaction with the provided services. It can help to adjust certain components of the future projects, such as location, future passenger traffic and also determine the priority projects required for implementation.

The proposed methodology can be characterized as integration of management elements and marketing elements into one system. To implement the system, you must meet the following conditions:

- identify goals and objectives, the need for research;

- determine the processes of the project, as well as the possible effects of its activities in the future;

- define the required criteria and methodology for assessing the performance and functioning of the work and processes.

This methodology can be realized by conduction a theoretical study with the definition of the target audience, the formulation of questions and questionnaires for monitoring the study. 
As a result, after monitoring the assessment of the social components effects, its will be possible to identify the main factors affecting the implementation of the HTIP and calculate the social effectiveness of the future HTIPs.

To assess the social significance of the project, it is possible to use the Scaling method.

This is a method of modeling real processes using numerical systems. This method is used to study mathematical phenomena, as well as the organization of data by empirical means, which are obtained through survey, observation, testing, questionnaire [13].

The scaling method allows the scientist to translate the qualitative characteristics of the object of study into mathematical numbers. The purpose of the Scaling method is to make a scale evaluation of quality characteristics. On of the most common Scaling methods are: the Layker scaling method, the Semantic differential scale, and the Step scale. These scales are discrete - allowing respondents to choose from the available answers offered in the survey [14].

Likert scale is an assessment of a speech, often symmetrical, usually five-point scale with the values. The scale of the Semantic differential is usually a seven-point scale, the extreme points of which are aligned two diametrically opposed to the semantic meaning of the concept [15]. The Step scale is a symmetrical 10 -point scale $(-5$ to +5 , there is no neutral value in this scale). The choice of scaling methods depends on the task and on the definition of what data should be obtained at the output of the model [16].

Using one of these scaling methods will help to obtain an objective assessment from the potential services consumers of HTIP and to solve strategically important issues at the stage of project planning.

\section{Conclusions}

In conclusion, it's important to figure out that the HTIPs, implemented by PPPs, should primarily be socially oriented, meet the requirements of improving the quality of services provided and improve the well-being of the population - as the main and final consumers of its-generated services [17].

Accordingly, in assessing HTIPs implemented by PPPs, it is necessary to develop a comprehensive assessment at both the micro level, including an assessment of the interaction between the public and private sectors, as well as at the macro level - assessment of the interaction with the external environment - consumers of services and assessment of the impact on the environment (territory development, branding issues, issues of investment climate, etc.).

\section{References}

1. V.I. Nabokov, A.K. Semenov, Basics of management: textbook, 7 edition (Trade corp. publishing «Dashkov and K», 2010)

2. V.V. Gloukhov, I.V. Ilin, V.I. Koposov, A.I. Levina, Asian Social Science 10(24), 209216 (2014)

3. A.I. Steshin, Otsenka effectivnosti investitsii v usl. Dokt. Diss (Saint-Petersburg, 2004)

4. O.I. Kulakova, Vestnik NSU. Series: Socio-economic Sciences 3, 14 (2013)

5. O.A. Donichev, T.B. Malkova, Evaluation of investment projects: theory and practice, monograph (Rusaints publishing, 2017)

6. D.P. Sergeeva, Innovation science, 11 (2015)

7. V.V. Glukhov, I.V. Ilin, A.I. Levina, Lecture Notes in Computer Science 9247, 543-553 (2015) 
8. A.

Zaborovskaya,

Corporate

Finance

(2008)

http://veb.ru/common/upload/files/veb/ppp/actions/20081021/c0810_zaborovskaya.pdf

9. A. A. Alaev, S. V. Kozlova, K. M. Malyutin, Financial journal 4, 12 (2015)

10. The Federal law № 224-FZ (2015)

11. E. S. Andreeva, Vestnik Kazanskogo tekhnologicheskogo universiteta 1, 300-303 (2013)

12. I.N. Tkachenko, Ya.V. Savchenko, Polythematic journal of scientific publications «Discussion» 8(49), 5 (2014)

13. A.V. Kataev, The theory of marketing researches (Kharkiv Institute of trade and Economics, 2014)

14. G.A. Cherchill, D. Yakobuddchi, Marketing research, textbook (Neva publishing, 2004)

15. E.A. Kasatkina, L.S. Latisheva, Marketing: textbook (Prospect publishing, Moscow, 2016)

16. A.O. Konstantinov, N.I. Koroleva, Youth scientific forum: Social and economic science: elec. collection of articles on the Mat. VII international. stud. science. practice 7(7), (2015)

17. Statistics, http://univer-nn.ru/statistika/koefficient-variacii/ (2017) 